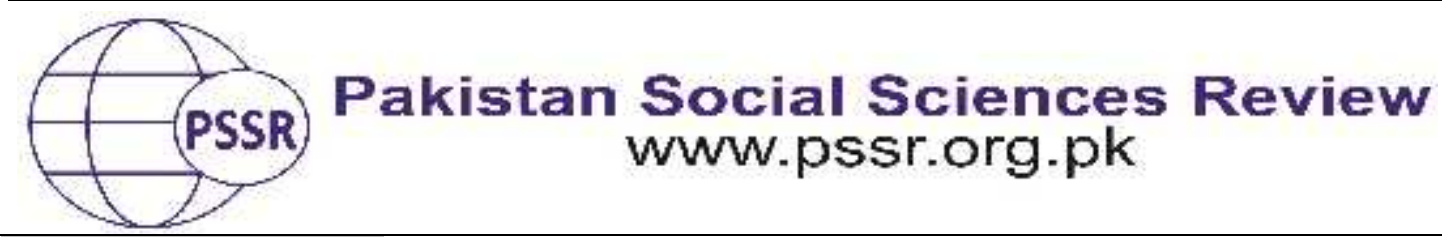

RESEARCH PAPER

\title{
Factors Affecting the Selection of Research Topic in Pakistan: A Case of Private Sector Universities
}

\author{
Dr. Fariha Gul ${ }^{*}$ Dr. Amna Yousaf 2 Saima Yaqub ${ }^{3}$
}

1. Assistant Professor, Department of Education, University of Management and Technology, Lahore, Punjab, Pakistan

2. Assistant Professor, Department of Education, University of Management and Technology, Lahore, Punjab, Pakistan

3. Lecturer in English, Onaizah Colleges, Onaizah, Saudi Arabia

\begin{tabular}{l}
\hline PAPER INFO \\
\hline Received: \\
December 21, 2020 \\
Accepted: \\
March 01, 2021 \\
Online: \\
March 15, 2020 \\
\hline Keywords: \\
Challenges, \\
Formative \\
Assessment, \\
Learning \\
Outcomes \\
Non-Formal, \\
Summative \\
Assessment \\
\hline *Corresponding \\
Author
\end{tabular}

\section{ABSTRACT}

This study aims to identify methods of selecting a topic while planning a research project. The students who are in the final years of research degree usually study a full course on research methodology. However, still, they feel that the selection of a research topic is not an easy task. To achieve this, targeted survey was carried out. The sample was selected by using convenient sampling technique from a total population of 1000 (approximately) students researching masters and doctoral degree levels from university of Management and Technology, Lahore. In total, one hundred students took part in the study. A self-developed instrument was used to collect data. The results indicate that there is a diversity of factors that influence students while selecting a research topic; more profound of which include personal experience and supervisor's area of expertise. The mean difference on the basis of gender was also found in factors of personal experience and availability of data. There was no difference on the basis of the level of study among students of master's and doctoral degree level. The future research studies can also combine the results of this study with other demographic variables, thus providing detailed fariha.gul@umt. information on factors that play a role in selecting a research edu.pk topic.

\section{Introduction}

The selection of research topic is one of the decisive factors in the successful completion of research projects at masters as well as a doctoral degree level. Sometimes it takes the form of a phobia, and students spent a lot of time searching for a good research topic. For this purpose, different strategies are adopted; including visiting the library, taking advice from senior fellows and teachers. 
However, still few end up with replica topics. The phenomena of choosing a problem that has already been researched in an indigenous or international context are preferred (as observed personally, discussion with national and international teachers). So, there is a need to identify factors that influence the selection of a research topic.

The research idea plays a key role in the development of a research project that contributes to the existing body of knowledge (Poock, \& Love, 2001). The most popular sources to develop a research idea are considered as literature review, personal experience, and observation. However, few other factors that can contribute to working in a specific field include the advisor's expertise and area of specialization, financial, and time constraints along with personal factors. All the factors that can influence the selection of a topic eventually have an impact on the quality of the results of research to some extent. So, it is necessary to identify the factors that are influencing more on students' choices of the topic in an indigenous context.

Academic research in the field of education has addressed a wide variety of topics ranging from research in core areas of education (including educational psychology, administration, assessment, curriculum, research) to interdisciplinary fields. From personal experience, observation of the list of theses done in previous years, communication with teachers and colleagues clarified that there are certain areas that are more popular among students than others. This general supposition also needs to be clarified by empirical evidence.

\section{Literature Review}

A common challenge faced by the students in the final year of their master studies is the selection of a topic for their degree thesis. This is one of the most important decisions; a graduate student makes at the end of his/her academic career. Most of the students at this stage are highly ambitious as they are on the border of academic and practical life (Lei, 2009). A lot of students face problems in either selecting their topic or realizing their real interest(Head \& Eisenberg, 2010). The selection of the wrong thesis topic may lead the students in a situation where they either cannot fulfill the requirements of a good thesis or try to compromise the quality of work.

From the writing instructor's perspective, Trocco reiterates that: "[It is] tough to persuade undergraduates to delve deeply into their research topics". He continues to discuss how this reluctance often translates into students writing superficial papers ( Trocco, 2000). Shenton and Dixon discuss students' tendency towards broad themes rather than topics (2004). Whitmire explains the relationship between epistemological beliefs of undergraduates and their influence on informationseeking behavior, including the topic selection stage (Whitmire, 2003). According to Head's and Eisenberg's report, $84 \%$ of the student's surveys agreed that the most challenging part of the course-related research process was getting started and $66 \%$ agreed that defining a topic was the most difficult task (Shahid \& Shahzad, 2013). 
Similar results were reported by Shahid and Shahzad where the selection of research topics was a severe problem for students due to the multicultural environment (2013).

Many factors are considered as a source for a selection of a research topic. For example, presenting or participating in any conference relevant to the subject area serves as one of the best sources to select a topic for research. Similarly, reading research papers in the relevant field serves as illuminating factors to identify the idea of research (Todd, 2004). Sometimes, for the professionals, day to day classroom observations and experiences serve as a source for the selection of a research topic (Celia, 2008). Similarly, the availability of resources for research, accessibility, time and previous studies also influence the selection of research topic for the dissertation (YalçÄn, BektaÅŸ, Öztekin, \&Karada, 2016). To identify an extensive list of factors that influence the selection of research topics, a comprehensive literature review was carried out. Following is a brief description of the factors that have been found through the literature review; a. Perceived ease: While choosing a thesis or dissertation research topic, the availability of reference materials should also be considered. This implies that students must initially check whether they can find sufficient information and closely related issues that will support students' research goals. In order to come up with something unique or original, students need to know what has been investigated previously, and then identify the gaps in knowledge in their respective field. Once students see how these gaps can be adequately filled, they will be able to come up with a final topic (Peters, 1997). Along the way, students should take appropriate coursework and write class research papers that may eventually be essential components of their thesis or dissertation; $b$. Advisors' area: If students accept a topic suggested by their faculty advisors, life can be more comfortable because students have their advisors' direct support and can save a tremendous amount of time searching for an ideal topic. The closer students' research is to their advisors' specialty area; the more likely their advice is to be helpful to students. In general, students who nestled under their advisors' wing finished early, compared to independent students (Churchill, \& Sanders, 2007); c. Future growth: one of the most crucial factors while selecting a research topic is the future prospects of the research study. The doctoral students get who enrolled in doctoral studies for professional and career growth, the selection of topic is aligned with their broader aim. Having enough chances of growth in the field in upcoming years serves as a strong factor for the selection of a research topic (Oplatka, 2009); d. Creativity: the motivation to solve a problem or present a new framework sometimes serves as a factor that influences the selection of a research topic; e. Current trend: Another aspect that is considered essential by researchers when designing their studies is the need to pay attention to the development of their field of study. Research should not focus on importing economic concepts but instead should examine local education policies, their affect education, school, and leadership, and their functions in implementation (Karadağ, 2009a); f. Literature review: In general, educational researchers utilize previous research to develop their conceptual and theoretical frameworks, and to provide qualitative (e.g., content analyses) and 
quantitative (e.g., meta-analyses) reviews of the literature, from which key findings are summarized (Ormrod, 2008a); g. Personal observation: Students must be intrinsically motivated because motivation increases research effort and energy, as well as enhances cognitive processes and research productivity (Ormrod, 2008b; Useem, 1997). The research problem or question must be worthy of students' time. Choosing a topic that is compelling enough to sustain further research is critical (Olalere, De Iulio, Aldarbag, \&Erdener, 2014). Research experts would suggest students to select a topic with which they are familiar or a topic in which they have a keen interest and enough preparation time to become an expert.

\section{Materials and Methods}

This study is exploratory in nature, and survey research design was used to achieve the target of study. The students who are researching at the master's and doctoral degree level were the population of the study. A convenient sampling technique was used to select a sample of the study. A self-developed instrument was used to collect data. Following is the detailed description of methodology;

\section{Sampling}

The targeted population of the study includes students enrolled in the faculty of social sciences in one of the largest private-sector universities of Pakistan. The enrolled students are more than 8000 in total, among them about 3000 are enrolled in Master, MPhil, and PhD programs in the school of social sciences in university of Management and Technology, Lahore, Pakistan. This school is composed of six departments.

The Sample of the study was composed of students who are working on their research projects as part of Masters, MPhil or PhD degrees. An approximate number of students working on a thesis is more than 600. As it was difficult to access all the students (due to time constraints) through using a proper sampling technique, so two methods were combined to select sample; convenience and snowballing. Convenience sampling is considered the most suitable for studies where access to population and mobility of the researcher is an issue due to financial and time constraints (Shahid\& Shahzad, 2013). As both of the reasons were prevailing while carrying out the current study, so, it was considered the most suitable selection process. In total, one hundred students took part in the study from a public sector university. The data was collected from postgraduate students irrespective of gender and subject in the field of social sciences.

\section{Instrument}

To achieve the target of the study, a self-developed research instrument was used. It was composed of two parts. The first part consisted of information regarding demographics including department, gender, subject, work experience, type of institute, etc. while the second part was composed of statements derived from factors that might influence the selection of the research topic. These factors were 
driven from a literature review as described previously. The following seven factors were identified through literature review;

Factor 1: Perceived ease/ ease of doing the research

Factor 2: Advisors area

Factor 3: Future growth:

Factor 4: Creativity

Factor 5: Current trend/ controversy / hot debate on topic

Factor 6: The literature review

Factor 7: Observation/ experience

The instrument was composed of 25 statements with a five-point Likert scale ranging from "strongly agree" to "strongly disagree".

\section{Validity and reliability of the instrument}

The instrument was validated via expert opinion from seven subject experts. The criteria defined for 'subject experts' were teachers at the university level who were supervising students for research at masters and doctoral levels. To calculate the reliability of the instrument, the value of Cronbach alpha was determined for each factor as well as the whole table.

Table 1

Reliability of the factors

\begin{tabular}{cccl}
\hline Factors & $\begin{array}{c}\text { Number of } \\
\text { statement }\end{array}$ & $\begin{array}{c}\text { Cronbach } \\
\text { alpha }\end{array}$ & \multicolumn{1}{c}{ Sample statements } \\
\hline F1 & 4 & 0.57 & This was an easy idea to understand \\
\hline F2 & 3 & 0.68 & $\begin{array}{l}\text { This relate to area of interest of my } \\
\text { advisor }\end{array}$ \\
\hline F3 & 4 & .069 & $\begin{array}{l}\text { The research in this area will help me in } \\
\text { my career advancement }\end{array}$ \\
\hline F4 & 3 & 0.71 & I wanted to contribute in literature \\
\hline F5 & 3 & 0.69 & $\begin{array}{l}\text { This field of study is currently popular } \\
\text { in global context }\end{array}$ \\
\hline F6 & 3 & 0.71 & I read a research paper on it \\
\hline F7 & 3 & 0.61 & $\begin{array}{l}\text { During lecture my teacher told us about } \\
\text { gap in research in current area }\end{array}$ \\
\hline Total all & & 0.67 & \\
\hline
\end{tabular}

\section{Results and Discussion}

As described earlier the data was collected from the students who were working on their research thesis, the survey form was filled by one hundred postgraduate students. The data was collected by the researcher personally, the 
respondents were told about confidentiality of the data, and consent was taken before filling the form. They were also clarified that participation in the research is absolutely voluntary and only those who agreed participated in the process. The study was carried out during the fall semester 2019 ( and data was collected in December, 2019) from postgraduate students who were at initial phases of research work. The data were analyzed by using SPSS software. Based on the objectives and research questions of the study, the experimental analysis includes descriptive statistics as well as ANOVA to compare means.

The first objective of the study was to identify factors that influence students' selection of certain research topics. The descriptive statistics were used to explore the frequency distribution of factors influencing students' selection of research topic.

Table 2

Descriptive statistics for the factors influencing students' criteria of selection of a research topic

\begin{tabular}{ccccc}
\hline & Range of scores & Mean & MPI & SD \\
\hline F1 & $4-20$ & 10.5195 & 2.62 & 3.09758 \\
\hline F2 & $3-15$ & 10.5195 & 3.50 & 2.38953 \\
\hline F3 & $4-20$ & 7.8831 & 1.97 & 3.20799 \\
\hline F4 & $3-15$ & 10.7273 & 3.57 & 2.91835 \\
\hline F5 & $3-15$ & 7.3506 & 2.54 & 2.13225 \\
\hline F6 & $3-15$ & 10.3636 & 3.45 & 3.57222 \\
\hline F7 & $3-15$ & 6.2727 & 2.09 & 2.06242 \\
\hline Total all & & 62.9610 & 2.73 & 7.51742 \\
\hline
\end{tabular}

Note: $\mathrm{N}=77$ : MPI = Mean per item, used to calculate tendency of data when Mean and Standard Deviation cannot give clear picture of results

The results indicate that the students have varied tendencies to select a research topic. The mean per item for each factor indicates that mostly the students were responding towards the lowest score of "disagree". Dispersion of results between "disagree" to "neutral" makes it difficult to make any interpretation regarding the identification of a particular factor that has a strong influence on students' tendency towards the selection of certain research topics. The most indecisive area was advisor's area, perceived ease, creativity, and literature review.

Similarly, objective 2 of the study was to explore the effect of demographic variables on the selection of research topics. An Independent sample t-test was applied to explore the mean difference between the level of students i.e., Masters, MPhil, or PhD.

Table 3

Independent sample t-test to examine the mean difference between gender and factors that influence on students' choices of research topics

\begin{tabular}{ccccccc}
\hline & Mean & \multicolumn{3}{c}{ SD } & T & Sig. \\
\hline Gender & Male & Female & Male & Female & & \\
\hline F1 & 10.697 & 10.697 & 3.426 & 3.426 & .582 & .574 \\
\hline
\end{tabular}




\begin{tabular}{ccccccc}
\hline F2 & 8.023 & 8.023 & 2.473 & 2.473 & .576 & .566 \\
\hline F3 & 9.720 & 9.720 & 3.164 & 3.164 & -.377 & .707 \\
\hline F4 & 10.767 & 10.767 & 2.589 & 2.589 & .135 & .893 \\
\hline F5 & 6.883 & 6.883 & 1.591 & 1.591 & .135 & $.030^{*}$ \\
\hline F6 & 11.348 & 11.348 & 3.766 & 3.766 & -2.216 &. $\mathbf{0 0 6}^{*}$ \\
\hline F7 & 6.744 & 6.744 & 2.012 & 2.012 & 2.320 & $.023^{*}$ \\
\hline Total all & 64.186 & 64.186 & 6.226 & 6.226 & 1.625 & .108 \\
\hline $\mathrm{N}=77, \mathrm{df}=75$ & & & & & &
\end{tabular}

It is evident from Table 3 that there was a significant difference between males and females on factor $5(p=.03)$, factor $6(p=.006)$, and factor $7(p=.023)$. All other factors have no significant difference based on gender.

Similarly, ANOVA was applied to identify the mean difference between the level of studies and the selection of the research topic. The following table shows that there was no significant difference between students' criteria to select a research topic regarding their study level i.e., masters, MPhil, or PhD.

Table 4

Mean difference between selections of research topic based on the level of study

\begin{tabular}{|c|c|c|c|c|c|c|c|c|}
\hline Factors & Mean & & & SD & & & $\mathbf{F}$ & Sig. \\
\hline & Masters & MPhil & PhD & Masters & MPhil & PhD & & \\
\hline $\mathrm{F} 1$ & 11.692 & 10.027 & 9.642 & 3.391 & 2.619 & 3.272 & 3.048 & .053 \\
\hline F2 & 8.076 & 7.973 & 7.285 & 2.381 & 2.597 & 1.815 & .543 & .584 \\
\hline F3 & 8.923 & 10.135 & 10.785 & 3.554 & 2.496 & 3.964 & 1.869 & .162 \\
\hline $\mathrm{F} 4$ & 9.884 & 11.351 & 10.642 & 2.702 & 3.318 & 1.645 & 1.986 & .144 \\
\hline F5 & 7.576 & 7.054 & 7.714 & 2.265 & 1.840 & 2.614 & .702 & .499 \\
\hline F6 & 11.153 & 10.135 & 9.500 & 4.095 & 3.137 & 3.589 & 1.125 & .330 \\
\hline F7 & 5.961 & 6.351 & 6.642 & 2.087 & 2.137 & 1.864 & .542 & .584 \\
\hline Total all & 63.269 & 63.027 & 62.214 & 7.394 & 7.682 & 7.807 & .090 & .914 \\
\hline
\end{tabular}

The table indicates that there was no significant difference among respondents based in their level of study.

\section{Discussion}

The main aim of the study was to identify factors that are influencing students' choices for selecting a topic for research in a specific area. The results are variant and indicate that many factors equally affect the choices of students while selecting the topic. The descriptive statistics were used to determine the most 
influential factor in preference of selection of topic. The results indicated that perceived ease, advisors' area, and availability of data were considered most important by the students. The results are supportive of previous research studies showing that students prefer to work in an area where data is most readily available as well as in space which is preferred by the supervisor (Sherfield, Montgomery\& Moody, 2005). The same results are also presented in a study carried out by Shahid and Shahzad stating that the students from the Asian context prefer to select topics that are more favored by the supervisor (Useem, 1997). The results also indicate that respondents prefer to choose research topics based on their personal observations and experience. This evidence is also in coherence with previous research studies indicating that in many fields, students try to choose a topic of research from personal experience (Sherfield, Montgomery\& Moody, 2005; Ameen, , Batool, \&Naveed, 2009). The results of the study verify the findings of a historical study on factors influencing the selection of dissertation topics, clarifying the factors of advisers' area of interest, and prospects of research to influence the job area of student (Olalere, De Iulio, Aldarbag, \&Erdener, 2014). The personal observation and experience of the scholar also play a positive role in selection of research topic, the results of current study also support this notion (YalçÄn, BektaÅ ̈̈, Öztekin, \&Karada, 2016).

Another objective of the study was to identify the difference in the selection of research topics based on gender and level of studies. The results indicate that the difference was found only in two factors of personal experience and the availability of data. These results are in coherence with the research study carried out by Useem(1997) who found availability of data as the most important factor that influences students' area of work. Due to impact of current pandemic, the resources and funding might be more influential factor in selection of research topic (Ameen, , Batool, \&Naveed, 2009). Similarly, no difference was found based on the level of study. The results are varied in nature, and there can be limitations of the research process as well as the sample size of the study.

\section{Conclusion}

The aforementioned study was carried out to identify the factors affecting the selection of research topics during research thesis. The results indicate that the most influential factors are the liking and expertise of the research supervisor on a certain topic. There is a need to carry out this research at a bigger level and with different geographical regions to identify the differences and generalizable factors that might influence the selection of research topic. 


\section{References}

Abrams, L. S. (2010). Sampling 'Hard to Reach' Populations in Qualitative Research:The Case of Incarcerated Youth. Qualitative Social Work, Vol 9, Issue 4, 536. https:/ / doi.org/10.1177/1473325010367821

Allwright, D., \& Bailey, K. M. (1991). Focus on the language classroom: an introduction to classroom research for language teachers. Cambridge: Cambridge University Press.

Ameen, Kanwal, SyedaHina Batool, S. H. \& Naveed, M. A. (2019). Difficulties Novice LIS Researchers Face While Formulating a Research Topic. Information Development 35, no. 4 592-600. https://doi.org/10.1177/0266666918774875

Celia W. (2008). Beyond administration and management: reconstructing the identities of professional staff in UK higher education, Journal of Higher Education Policy and Management, 30:4, 375-386,

Churchill, H., \& Sanders, T. (2007). Getting your PhD: An insiders' guide. London: Sage Publications.

Head, A. J., \& Eisenberg, M. B. (2010). Truth be told: How college students evaluate and use information in the digital age. Project Information Literacy Progress Report. DOI:10.2139/ssrn.2281485

Isaac, P.D., Koenigsknecht, R.A., Malaney, G.D.(1989) . Factors related to doctoral dissertation topic selection. Research in Higher Education 30:357-373 https://doi.org/10.1007/BF00992560

Karadağ, E. (2009a). A thematic and methodological reviewing on doctoral thesis which made at the area of education sciences in Turkey: A case study. (Doctoral dissertation, Marmara University, İstanbul, Turkey).

Lei, S. A. (2009). Strategies for finding and selecting an ideal thesis or dissertation Topic: A review of literature. College Student Journal, 2009 43(4):1324-1332.

Olalere, A. A., De Iulio, E., Aldarbag, A. M., \& Erdener, M. A. The dissertation topic selection of doctoral students using dynamic network analysis. International Journal of Doctoral Studies, 2014 9: 85-107. https://doi.org/10.28945/2031

Olalere, A. A., De Iulio, E., Aldarbag, A. M., \&Erdener, M. A. (2014). The dissertation topic selection of doctoral students using dynamic network analysis. International Journal of Doctoral Studies, 2014 9: 85-107.

Oplatka, I. (2009). Educational administration as a contextually based field of study: Reflections from the 2008 Commonwealth Council for Educational Administration and Management Conference in South Africa. International Studies in Educational Administration. 2009 37(3): 3-19. 
Ormrod, J.E. (2008a). Education psychology: Developing learners (6th ed.). Upper Saddle River, New Jersey: Pearson/Merrill.

Ormrod, J.E. (2008b). Human learning (5th ed.). Upper Saddle River, New Jersey: Pearson/ Prentice Hall.

Peters, R.L. (1997). Getting what you came for. New York, New York: Farrar, Stratus and Giroux.

Poock, M.C., \& Love, P.G. (2001). Factors influencing the program choice of doctoral students in higher education administration, NASPA Journal. 2001 38(2): 203-223.

Shahid, M., \& Shahzad, R. M. K. (2013). Selection of a Graduate Thesis Topic in a Multicultural Educational Environment. Presented at the LärarlärdomHögskolepedagogiskkonferens, Kristianstad. .oai:DiVA.org:bth-6400

Shenton, A. K., \& Dixon, P. (2003). Issues arising from youngsters' informationseeking behavior. Library E Information Science Research. 2004, 26(2), 177-200.

Sherfield, R.M., Montgomery, R.J., \& Moody, P.G. (2005). Cornerstone: Building on your best (4th ed.). Upper Saddle River, New Jersey: Pearson/Prentice Hall.

Todd, R.W., Thienpermpool, P., \&Keyurawong, S. (2004). Measuring the coherence of writing using topical-based analysis. Assessing Writing, 9, 85-104.

Trocco, F. (2000). Encouraging students to study weird things. The Phi Delta Kappan. 81(8), 628-631.https:/ / digitalcommons.lesley.edu/jppp/vol4/iss1/7

Useem, B. (1997). Choosing A Dissertation Topic", Publisher: American Political Science Association, University Of New Mexico, 30 (2): 213

Whitmire, E. (2003). Epistemological beliefs and the information-seeking behavior of undergraduates. Library $\mathcal{E}$ Information Science Research, 25(2): 127. DOI:10.1016/S0740-8188(03)00003-3.

Witze, A., Subbaraman, N., Viglione, G., Callaway, E., Mallapaty, S., Cyranoski, D., Ledford, H., \& Gibney, E. (2020). Even after the worst of the coronavirus pandemic passes, its effects could permanently alter how scientists work, what they study and how much funding they receive. Nature 582: 162-164 doi: https://doi.org/10.1038/d41586-020-01518-y

YalçÄn, M., BektaÅ̈̈, F., Öztekin, Ö., \&KaradaÄ̈̈, E. (2016). Factors affecting the identification of research problems in educational administration studies. Educational Sciences: Theory $\mathcal{E}$ Practice, 16: 23-52 http://dx.doi.org/10.12738/estp.2016.1.0206 